\title{
ARQUEOLOGÍA Y PLANIFICACIÓN TERRITORIAL EN CHILE, SITUACIÓN ACTUAL Y PERSPECTIVAS. EL CASO DE ESTUDIO DE LA PROVINCIA DE CAUTÍN, REGIÓN DE LA ARAUCANÍA
}

\author{
ARCHAEOLOGY IN TERRITORIAL PLANNING FOR CHILE, CURRENT \\ SITUATION AND PERSPECTIVES. A CASE STUDY OF CAUTÍN PROVINCE, \\ REGION OF ARAUCANÍA
}

\author{
Doina Munita ${ }^{1}$ Fernando Peña-Cortés ${ }^{2}$ y Aldo Farías ${ }^{3}$
}

\begin{abstract}
Se propone un modelo general de trabajo de incorporación de la arqueología en la planificación territorial de Chile, considerando al componente arqueológico como propio del medio físico. Mediante la revisión de la normativa relacionada, los instrumentos de planificación territorial y el estado actual de la consideración a nivel institucional de los recursos patrimoniales arqueológicos, se pretende evidenciar su importancia y la necesidad de su adecuado tratamiento en el proceso de ordenamiento del territorio. Para esto se modela la información arqueológica disponible para la Provincia de Cautín, en la Región de La Araucanía, como base para que dicho esquema sea replicable en otras regiones del territorio nacional.
\end{abstract}

Palabras claves: arqueología, medio físico, planificación territorial, Araucanía - Chile.

A general model is proposed for the incorporation of archaeology in the territorial planning for Chile, considering the physicality of archaeological resources. By means of the review of relevant regulations, the instruments of territorial planning, and current considerations of institutional levels for archaeological resources, we try to demonstrate the importance and the need for appropriate classifications of territories. For this, we use the model of archaeological resources for the Province of Cautín, in the region of Araucanía, and hope this scheme can be replicated in other regions of the nation.

Key words: Archaeology, landscape, territorial planning, Araucanía - Chile.

El desconocimiento de la presencia y manejo de los recursos arqueológicos de un territorio se convierte hoy en día en el mayor impedimento para su tratamiento y es causa además de procedimientos inadecuados de intervención, llegando incluso a contravenir la legislatura vigente (p.ej. Ropert y Saavedra 2004). ¿Cuál es la relevancia de la arqueología en términos territoriales?, ¿de qué manera puede ser incorporado el componente arqueológico en los instrumentos de la planificación territorial $[\mathrm{PT}]^{1}$ en Chile? Como respuesta a estas preguntas, se pretende entregar una visión disciplinaria de la condición del componente arqueológico, considerando como ejemplo a la Provincia de Cautín en la Región de La Araucanía y proponiendo a través de su estudio estrategias de trabajo que permitan incluir al patrimonio arqueológico en las etapas de planificación territorial.

Una condicionante para evitar pérdidas irreparables en términos patrimoniales, es la aplicación de adecuados esquemas de trabajo en las etapas de planificación en el ordenamiento territorial [OT], considerando a éste como un proceso "macro" de acciones concertadas y dirigidas por el Estado, para una organización del uso del territorio (p.ej. Massiris 2002; Gómez 2008). La consideración del patrimonio arqueológico en las fases iniciales del OT puede llegar a convertirse en potencial instancia de desarrollo y acumulación de conocimiento en forma sistemática, como un importante complemento de

1 Programa de Magíster en Planificación y Gestión Territorial, Escuela de Ciencias Ambientales, Facultad de Recursos Naturales, Universidad Católica de Temuco. Casilla 15-D. Temuco, Chile. doinamunita@yahoo.com

2 Laboratorio de Planificación Territorial, Núcleo de Investigación en Estudios Ambientales, Facultad de Recursos Naturales, Universidad Católica de Temuco. Casilla 15-D. Temuco, Chile. fpena@uctemuco.cl

3 Carelmapu 2475, Valdivia. aldo.farias@gmail.com 
las siempre escasas investigaciones científicas. Bajo este prisma y dado el carácter tangible e inmueble de los sitios arqueológicos, además de su intrínseca valorización sociocultural, se debe asumir su carácter económico, considerando a este tipo de entidades como recursos no renovables, propios del medio físico (Fernández 2008). Actualmente en Chile, el carácter económico de estos bienes se encuentra principalmente determinado por la demanda de su registro, siendo éste de carácter científico o relevado en el marco de proyectos de desarrollo e inversión. Si bien la legislación chilena protege los recursos arqueológicos por el solo ministerio de la ley ( $\mathrm{N}^{\circ} 17.288$ de Monumentos Nacionales) y existe un procedimiento claro acerca de las intervenciones sobre ellos, una vez determinadas las necesidades de su registro, rescate y/o preservación no existen normas detalladas acerca de planes de manejo a nivel territorial.

Ante esta realidad, se hace necesaria una revisión de las políticas culturales, ambientales y territoriales que presentan vínculos directos o indirectos con el componente patrimonial arqueológico, contextualizándolo en los Instrumentos de Planificación Territorial [IPT $]^{2}$, además de considerar criterios y experiencias extranjeras que lo involucren (p.ej. Llavori de Micheo 1998; Fernández 2008; Gómez 2008) y entreguen orientaciones definidas para la toma de decisiones. Esta información se convierte en el sustento de una propuesta de incorporación efectiva, mediante metodologías y procedimientos existentes e IPT vigentes.

\section{Arqueología en Planificación Territorial}

La acumulación de conocimiento acerca del pasado de las culturas originarias (arqueológicas y etnográficas) es considerada como una herramienta para el desarrollo cultural y territorial de los países y se ha convertido en un tema de relevancia global (p.ej. International Council on Monuments and Sites [ICOMOS] 2007; Centro de información de las Naciones Unidas para México, Cuba y República Dominicana [CINU] 2010). De acuerdo a esto, valorizar la temática a nivel nacional se vuelve prioritario, pretendiendo resolver el desequilibrio existente entre la presencia de patrimonio cultural arqueológico y su actual tratamiento en el territorio. Evidencias de este desequilibrio son: (a) que el tema arqueológico ha sido relegado a los niveles finales de consideración en las políticas territoriales, (b) el desarrollo y estado de la investigación en arqueología presenta un escaso impacto social, (c) que existe un alto grado de desconocimiento de los ciudadanos acerca de la normativa y los procedimientos arqueológicos aplicables ${ }^{3}$ y (d) aún es escaso el desarrollo de iniciativas estatales de levantamientos sistemáticos, así como de normalización de la información arqueológica existente.

Asumiendo el valor sociocultural y económico del patrimonio arqueológico como recurso inmerso en el medio físico y, por lo tanto, como un componente relevante del territorio y la oferta del espacio ${ }^{4}$, su consideración en el OT presenta, al menos, dos dimensiones de trabajo: (1) la factibilidad de la incorporación del componente arqueológico en las etapas de planificación y gestión territorial y (2) la aplicación del trabajo de planificación en proyectos de índole arqueológica, atendiendo a las características ambientales y políticas de las diferentes áreas de estudio. Si bien el mayor valor de la información arqueológica está dado por su potencialidad para la producción de conocimiento, es innegable su carácter económico. Bajo este enfoque, la Economía de la Cultura -en cuyo marco se considera a las transformaciones de la economía productiva hacia los servicios destinados al consumo final, como generadoras de un sector innovador (p.ej. Herrero 2002)- permite inferir las implicancias territoriales del patrimonio arqueológico. Entre los servicios presentes se encuentran los recreativos, el turismo, aquellos enfocados hacia la producción cultural y el ocio, siendo todos ellos posibles de vincular con la difusión del conocimiento de los resultados de las investigaciones científico-arqueológicas. Las implicancias territoriales en las economías modernas se asocian al declive de algunas zonas de tradición industrial y a la emergencia de nuevos centros de desarrollo de los mencionados servicios.

El desarrollo de la arqueología y la planificación territorial ya ha sido practicado en España (p.ej. Fernández 2008; Llavori de Micheo1998); a su vez, también se registran referencias en países de habla inglesa. En estos últimos, se observa un comienzo del interés temático en la década de 1970, aunque con un enfoque más cercano a la preservación de monumentos arquitectónicos (Rodríguez 1996), a la valoración patrimonial (Carver 1996) y la arqueología aplicada a proyectos de desarrollo. Por su parte, en América Latina, hacia la década de 1990 la relación entre arqueología y PT era considerada como una temática incipiente (Aceituno 1998), 
aunque en los últimos años se observa un aumento de la literatura específica (p.ej. López et al. 2010) y su aplicación (p.ej. Grupo de Educación Gestión en Cultura y Educación Ambiental 2009; Gobierno Departamental de San José 2011).

Para el caso de Chile, escasos trabajos dan cuenta de la relación entre la arqueología y la administración territorial, correspondiendo al análisis la situación del patrimonio arqueológico sobre todo en proyectos de desarrollo e inversión. Un ejemplo de ello lo constituye la realidad de Rapa Nui, donde el patrimonio arqueológico es un pilar de la identidad local, así como también se convierte en el principal responsable del ingreso de recursos. Una mirada por la historia de la isla, específicamente a los planes de manejo aplicados en el Parque Nacional Rapa Nui y su pretendida zonificación, demuestra que la falta de políticas y planificación había redundado en la inoperancia del sistema -al menos hasta el año 2004-, evidenciando que el desarrollo de obras públicas ha sido uno de los responsables de la pérdida del patrimonio cultural de la isla. Asimismo, este caso demuestra la relevancia que tiene la aplicación de políticas territoriales, planificación preventiva y la adecuada ejecución de los Estudios de Impacto Ambiental [EIA] en áreas de relevancia arqueológica (Ramírez 2004).

En cuanto a los enfoques y procedimientos de la disciplina arqueológica, es importante señalar que actualmente existe un consenso mundial en la ocurrencia de cambios, principalmente referidos al quehacer relacionado con la arqueología aplicada, sus implicancias y su contextualización territorial. Los enfoques teórico-prácticos más relacionados al vínculo entre arqueología y PT corresponden a la arqueología aplicada (p.ej. en el Servicio de Evaluación Ambiental [SEA]), la Arqueología Espacial (p.ej. Araneda 2002; Hodder y Orton 1990) y la Valoración del Patrimonio Arqueológico (p.ej. Adán et al. 2009; Carver 1996). En este último punto cabe mencionar a la valoración patrimonial como parte del proceso de planificación territorial, mientras continúa siendo materia de trabajo en la generación y aplicación de políticas culturales y territoriales. Carver (1996) da cuenta de valoraciones previas para el patrimonio cultural, que no han resuelto el problema de la valoración social. A su vez, expone a través de ejemplos cotidianos el proceso de cómo se ha vinculado el tema del patrimonio cultural a la valoración del medio ambiente, observando la complejidad del tema de acuerdo al momento histórico en que se percibe tal patrimonio (situación variable de generación en generación). Como parte de su entendimiento, da cuenta de dos visiones contrapuestas, donde la postura de los llamados "empiricistas" se enfrenta a los "investigadores", siendo el de los primeros un acercamiento más profesional y el segundo, más académico. Según el autor, los "empiricistas" concebirían al patrimonio arqueológico existente como tal e independiente de los seres humanos, mientras que los "investigadores", si bien aceptan su existencia por sí mismo, no lo concebirían como "recurso", sino hasta confirmados los objetivos de investigación. Esta segunda postura es descrita como una "arrogancia académica", mencionando a esta confrontación teórica como improductiva y como una de las razones de la desvinculación de las políticas con relación a la gestión del patrimonio arqueológico. Según lo expuesto, se concluye que los trabajos de investigación académica son insuficientes para el adecuado desarrollo arqueológico, siendo necesaria también la implementación de proyectos de manejo o gestión a nivel institucional-gubernamental.

Un cuestionamiento básico es cómo resolver el problema de la valoración del patrimonio arqueológico en la planificación territorial; con qué criterios es posible establecer que un yacimiento arqueológico debe ser registrado y caracterizado, excavado y/o preservado. En este punto, cabe hacer hincapié en que no solo los yacimientos que presentan monumentalidad son relevantes de preservar o investigar, sino que el concepto de depósito potencial de investigación corresponde al término a tener en cuenta en la gestión del patrimonio arqueológico y por ende en su regulación (p.ej. Ley $\mathrm{N}^{\mathrm{o}} 17.288$; Fernández 2008). Este modelo propone que todo el territorio se vuelve de interés arqueológico, dada la eventual presencia de este tipo de depósitos en él ${ }^{5}$.

Bajo esta perspectiva, para la gestión del patrimonio arqueológico, la secuencia de trabajo en la PT consideraría etapas que en Chile sólo han sido aplicadas en forma incipiente y parcial [p.ej. POT Lago Ranco 2007 (Laboratorio de Planificación Territorial [LPT-UCT] 2007; Mera y Munita 2007); Estudio Diagnóstico Patrimonio Cultural de la región de Los Ríos 2009-2010 (Ministerio de Obras Públicas [MOP] 2010; Adán 2010)] y que corresponden a las etapas iniciales del trabajo patrimonial en el territorio: (1) la generación de cartas arqueológicas sectoriales y generales, (2) la generación de agendas de investigación, (3) el otorgamiento de valoración 
a los depósitos de acuerdo a sus características y, (4) el cumplimiento de la agenda de investigación (Adán et al. 2009; Fernández 2008).

\section{Normativa Relacionada con la Arqueología y el Territorio}

A través de la contextualización legal internacional, es posible observar la relevancia del patrimonio arqueológico en términos territoriales. En este contexto cabe considerar tratados y convenciones como la Convención de Malta ${ }^{6}$ y la Convención de Lausana ${ }^{7}$, que hacen especial referencia a los recursos arqueológicos como patrimonio cultural en el territorio y establecen también la idea de cómo han evolucionado la percepción y el trato hacia la arqueología en el tiempo, fortaleciendo la idea de la transformación en las "mentalidades" de los diferentes países hacia la gestión del patrimonio cultural arqueológico. Otros puntos importantes que se desprenden del marco normativo internacional (p.ej. Nueva Delhi 1956, Londres 1969, San Salvador 1976, Lausana 1990 y Malta 1992), son: la conservación de zonas de interés arqueológico, la necesidad de generar catastros arqueológicos (como figura preventiva), la participación de arqueólogos en las políticas de ordenación y la interacción disciplinaria en las instancias de planificación (Mariné 1996; Querol y Martínez 1996). Si bien estas convenciones no han sido suscritas o ratificadas por el Estado de Chile, sería deseable que actuaran como una tendencia en la fundamentación de futuras políticas patrimoniales relacionadas al territorio, debido a lo pertinente de sus contenidos ${ }^{8}$.

En Chile, los sitios arqueológicos son reconocidos como Monumentos Nacionales por el solo ministerio de la ley $\left(\mathrm{N}^{\circ} 17.288\right)$, sin necesidad de ser declarados como tal (a diferencia del patrimonio correspondiente a los Monumentos Históricos), lo que tiene relación con su naturaleza y grado de importancia para la Historia, el Arte y la Ciencia. En cuanto a la normativa ambiental, desde el año 1994 hasta el 2012 se ha incluido el tema arqueológico en la evaluación de los distintos tipos de proyectos de inversión, a través de la aplicación del artículo 11 de la Ley de Bases del Medio Ambiente $\mathrm{N}^{\circ} 19.300^{9}$ y su respectivo reglamento, aludiendo a la Ley $\mathrm{N}^{\mathrm{o}} 17.288$ de Monumentos Nacionales y considerando al Consejo de Monumentos Nacionales $[\mathrm{CMN}]$ como una institución evaluadora en el Servicio de Evaluación Ambiental [SEA]. Éste, como sistema estatal, puede ser considerado como el más importante mecanismo de intervención arqueológica preventiva, inmerso en las líneas del desarrollo económico del país.

Fuera del SEA, la aplicación de la Ley de Monumentos Nacionales No 17.288 de 1970 y el Reglamento No 484 de 1990 del Ministerio de Educación, a través de la intervención del CMN, se realiza mediante un trabajo normativo reactivo, ante los diferentes hallazgos ocurridos producto del desarrollo urbano y rural. Por su parte, la protección del patrimonio arqueológico se establece en la Ley Indígena $\mathrm{N}^{\circ} 19.253$, como parte del reconocimiento de las culturas ancestrales e indirectamente en el Convenio 169 sobre pueblos indígenas y tribales en países independientes de la Organización Internacional del Trabajo.

Estos mecanismos de acción permiten regular el impacto sobre los recursos arqueológicos, la obtención de información y el levantamiento de los materiales culturales y contextos existentes en las áreas intervenidas o por intervenir en todas las regiones del territorio nacional ${ }^{10}$.

En el marco de la planificación territorial nacional, los monumentos nacionales como materia deben ser contemplados en los Planes Regionales de Ordenamiento Territorial [PROT], instrumentos que -en el marco del proceso de traspaso de competencias a los Gobiernos Regionales- corresponderán a la redefinición de los Planes Regionales de Desarrollo Urbano [PRDU], siendo sus componentes de análisis diagnóstico y de prospectiva, lo urbano, rural, costero y las cuencas hidrográficas (Subsecretaría de Desarrollo Regional y Administrativo [SUBDERE] 2011). Con relación a los instrumentos normativos de la PT (los IPT), se cuenta con la consideración del patrimonio cultural en los ámbitos de acción de los Planes Reguladores Intercomunales [PRI] -para las zonas rurales y urbanas-, en el marco de la Evaluación Ambiental Estratégica [EAE] y de acuerdo a la Ordenanza General de la Ley General de Urbanismo y Construcciones [OGUC]. Asimismo, se encuentra incorporado legal y directamente para las áreas urbanas, en los expedientes (Memoria explicativa, Ordenanza Local y Planos) de los Planes Reguladores Comunales [PRC]. A través de esto, se identifica que no sólo es factible la consideración del componente arqueológico en el ordenamiento territorial de las regiones, sino que a su vez corresponde a un nivel de información que debe ser levantado, al menos en áreas urbanas, 
según las normas establecidas ${ }^{11}$. Por su parte, el patrimonio cultural arqueológico también es materia de relevancia en planes o instrumentos indicativos (p.ej. Pladetur, Planes de Ordenamiento Territorial locales [POT]).

\section{Estado actual de la consideración del Patrimonio arqueológico a nivel institucional}

Como unidad dependiente de la Dirección de Bibliotecas, Archivos y Museos [DIBAM $]^{12}$, el Centro Nacional de Conservación y Restauración [CNCR] cuenta desde el año 2007 con la Unidad de Geoinformación del Patrimonio [UGP], encargada del área de Patrimonio del Sistema Nacional de Coordinación de Información Territorial [SNIT] (Ladrón de Guevara et al. 2007). En términos arqueológicos, esta unidad ha implementado los "Estándares Mínimos de Registro del Patrimonio Arqueológico" [2010], sistema de registro unificado que permitirá un avance en cuanto a la recopilación de información existente del patrimonio arqueológico chileno y actúa como un aporte interdisciplinario concreto a nivel central para el tratamiento de la relación entre el patrimonio arqueológico y territorio.

En cuanto al ámbito regional, en el acápite de Identidad Regional de la Estrategia de Desarrollo Regional de La Araucanía (Gobierno Regional de La Araucanía [GORE] 2010), se menciona la incalculable riqueza natural, histórica y cultural de la región, sin incorporar el concepto de patrimonio, implícito en estos tres aspectos del territorio y su población. Por su parte, en las líneas de acción de los objetivos generales, se pretende "Generar una Agenda Consensuada con los diversos actores de la sociedad regional que permita implementar el proceso de la Responsabilidad Cultural Araucanía" (GORE 2010:79); este concepto de Responsabilidad Cultural surge a partir del Programa de Fortalecimiento de Identidad Regional (SUBDERE 2011), donde se consideró como un pilar de la construcción de la identidad cultural de la Araucanía a los antecedentes arqueológicos generales conocidos, a nivel de microestudio (Instituto de Desarrollo Regional-Universidad de La Frontera [IDER-UFRO] 2008; Mera y Munita 2008). En este sentido, los antecedentes arqueológicos otorgaron profundidad temporal o larga data a la diversidad cultural y a los procesos de apropiación del territorio y transformaciones productivas, constituyéndose en parte de la base de la "construcción y rompimiento del marco intercultural simétrico en La Araucanía" como parte de la comprensión de la realidad regional. En este punto cabe reiterar que, en términos arqueológicos, en la Región de La Araucanía existen importantes brechas cronológicas y espaciales. Los períodos y complejos culturales registrados se encuentran en un proceso de constante definición, dado que cada recurso arqueológico en sí otorga nuevos datos que permiten reconocer paulatinamente las diferentes realidades del pasado.

En la Política Cultural de la Región de La Araucanía 2005-2010 se menciona la presencia de sólo dos Monumentos Arqueológicos y 37 Monumentos Históricos (Consejo Nacional de la Cultura y las Artes [CNCA] 2005), cifras que consideran exclusivamente a los Monumentos declarados mediante Decretos Supremos, desconociendo la cantidad real de recursos arqueológicos reconocidos en el territorio.

En cuanto a su consideración en la PT, pocos casos de planes reguladores comunales mencionan recursos arqueológicos en las recopilaciones de datos (inventarios) y la realización de diagnósticos en las memorias explicativas; tampoco son considerados en los mapas y zonificaciones. De existir información arqueológica expuesta en el componente de patrimonio de los PRC, ésta es escasamente representativa, situación que puede ser confrontada con los resultados de este trabajo.

La consideración patrimonial se establece principalmente a través de la normativa vinculada (Ley $\mathrm{N}^{\circ} 17.288$ ), pero se detecta que no existe una lectura de la ley que repare en la presencia de patrimonio cultural arqueológico como una fuente de recursos tangibles manifiestos en el territorio. Los datos arqueológicos no se registran posicionados, lo que redunda en que los antecedentes no presentan una dimensión física a nivel virtual y no tengan representatividad efectiva en los IPT, quedando excluidos, por tanto, de las etapas de planificación y gestión del territorio en el contexto urbano de cada comuna.

Un elemento crítico del diagnóstico de la consideración del patrimonio arqueológico a nivel institucional -regional y sectorial en la Provincia de Cautín- es la falta de información sistematizada acerca de su presencia, así como la ausencia de iniciativas de generación de datos concretos que permitan trabajarlo. Se observa que en los documentos, pese a las buenas intenciones de integrarlo en los planes de desarrollo, no se da lugar 
a consideraciones territoriales de preservación y/o manejo de los recursos, existiendo un tratamiento retórico del tema y una conformidad con la escasa información recabada, asumiendo que lo que se ha logrado conseguir es "aquello que se conoce", estando muy alejados del estado del arte y las potencialidades de la arqueología como un recurso regional.

\section{Métodos de Trabajo y Área de Estudio}

Con el fin de hacer un diagnóstico de la situación del componente arqueológico en la planificación del territorio a nivel regional y obtener información para sostener las propuestas, se trabajó con la Provincia de Cautín en la Región de La Araucanía como área de estudio.

Las fuentes comparadas de información arqueológica de la Provincia corresponden a un conjunto de datos recogidos en forma sistemática y aquellos existentes en la bibliografía especializada (Figura 1). Para este trabajo se recopiló la información proveniente de 49 fuentes en las que se obtuvieron resultados positivos, correspondientes a documentos y bases de datos tanto publicadas como digitales, obteniendo un total de 346 recursos (Munita y Farías 2011).

\section{Generación de Catastro y SIG}

La información territorial relativa al componente arqueológico fue ordenada mediante la utilización de un sistema de información geográfica [SIG], de acuerdo a unidades territoriales naturalmente definidas (subsubcuencas hidrográficas) y unidades administrativas (comunas), para someter los datos recabados a posteriores análisis exploratorios (comparación de grupos de datos de diferentes procedencias), realizando un diagnóstico del estado de la arqueología a nivel territorial en la Provincia. La metodología empleada para la localización de los recursos arqueológicos comenzó con un proceso de recopilación de antecedentes donde se obtuvo variada información relativa a la localización mediante coordenadas y el sistema de referencia con el cual fueron capturadas (proyección y datum). Esta información fue incluida en una tabla Excel® (Munita y Farías 2011) ${ }^{13}$ y utilizando el programa ArcInfo 9.3® se creó una cobertura de información cartográfica de

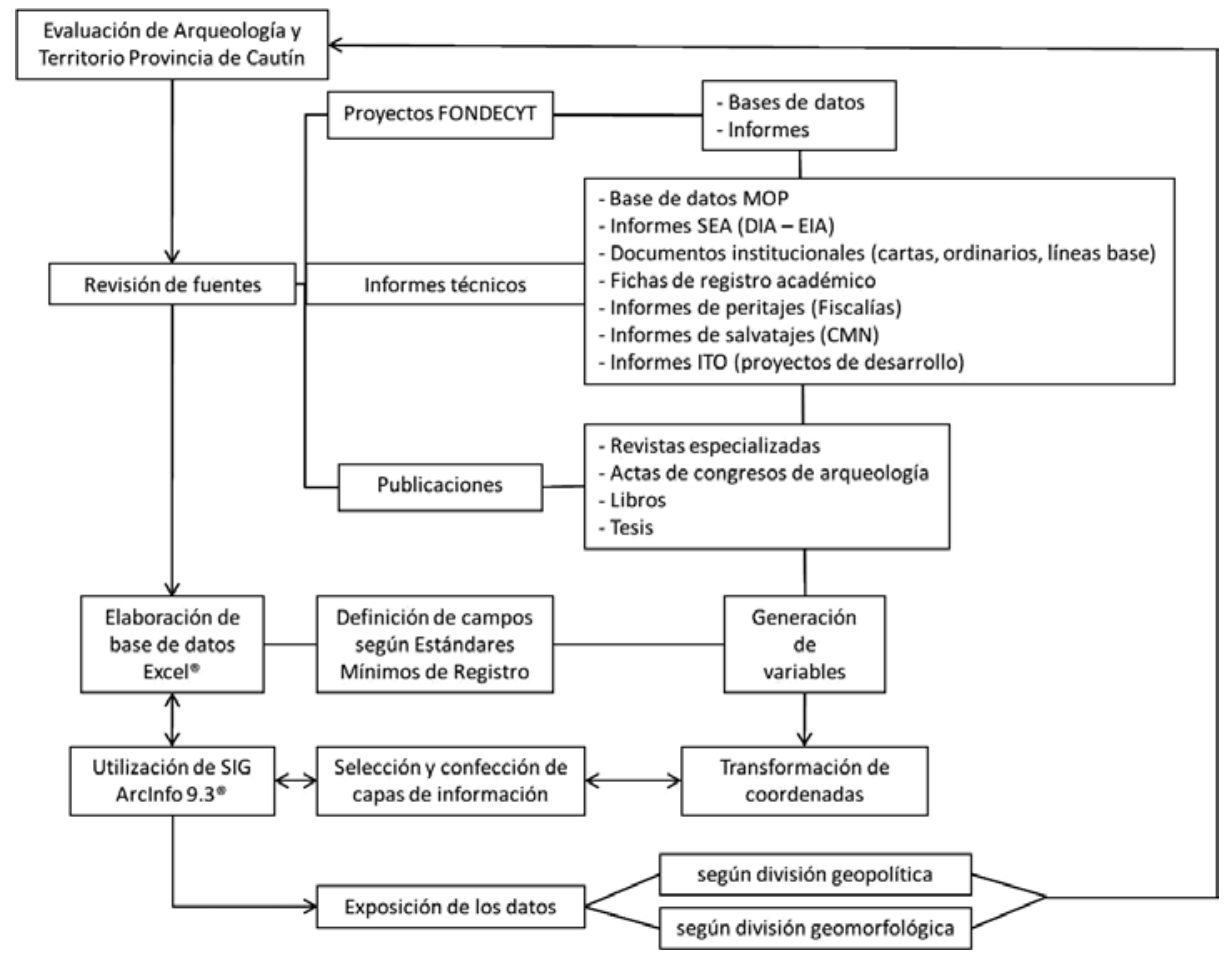

Figura 1. Esquema metodológico seguido en la recopilación, ordenamiento, exposición y análisis de los datos. Methodological scheme followed in the summary, classification, exhibition and analysis of data. 
puntos. Para cumplir con los estándares definidos por el SNIT se procedió a transformar dichas coordenadas al sistema WGS84 Huso 18 Sur, mediante el programa de transformación de datum del Instituto Geográfico Militar [IGM]. Para la subdivisión político-administrativa se utilizó información de límites administrativos del MOP (escala 1:50.000) y para la subdivisión geomorfológica y sistémica -a nivel ambiental- se utilizó información de cuencas hidrográficas proveniente de la Dirección General de Aguas [DGA] (escala 1:100.000). Por su parte, la labor del traspaso de datos de posicionamiento respondió a los "Estándares mínimos de registro del Patrimonio Arqueológico" (UGP-CNCR2010) y a la generación de otros campos, cuyas variables tienen relación con las características de las fuentes.

\section{Resultados}

\section{La importancia del origen de los datos}

La ejecución de modelos de trabajo que reconozcan y consideren la presencia del patrimonio arqueológico en la planificación territorial de una región, se vincula con una correcta aplicación de la normativa relacionada y la integración de la información temática disponible. Paralelamente, la generación de nueva información a nivel territorial permite tener una visión clara de las características y potencialidades de cada territorio, consolidar el cuerpo de datos de una región y es de primer orden en las etapas de valoración. La cantidad y calidad de información recabada condicionarán la calidad de la muestra, dependiendo de ésta una adecuada toma de decisiones (Rozzi et al. 2006).

La muestra correspondiente a datos registrados de forma sistemática en términos territoriales corresponde a los resultados de las prospecciones realizadas en el marco del proyecto 1060216 financiado por el Fondo Nacional de Desarrollo Científico y Tecnológico [FONDECYT] (Adán et al. 2006), cuya metodología fue diseñada con relación a las características geomorfológicas, ambientales y culturales de áreas de estudio definidas, de acuerdo a una distinción y ordenamiento en base a cuencas hidrográficas (Munita et al. 2010). Esta muestra pudo ser posicionada adecuadamente, a través de coordenadas UTM en terreno, con datum conocido. Por su parte, la información procedente de trabajos desarrollados en el marco del SEA fue considerada como un segundo cuerpo de datos, que si bien está adecuadamente georreferenciado, en términos territoriales es conformado de acuerdo a objetivos vinculados a proyectos puntuales de desarrollo e inversión ${ }^{14}$. Finalmente, el tercer cuerpo de datos: las publicaciones, de alta relevancia en cuanto a su calidad descriptiva e interpretativa del registro, presentan importantes complicaciones para su posicionamiento. En términos generales, el emplazamiento exacto de los sitios arqueológicos en publicaciones previas al año 2000 solo es referencial ${ }^{15}$.

A través de la revisión de las fuentes arqueológicas para la Provincia, se registra que la información territorial precisa es difícil de obtener, tanto de las fuentes publicadas en la bibliografía especializada como de las bases de datos relevadas por el MOP en el marco del proyecto "Ubicación de Restos Arqueológicos en Cuencas Priorizadas", ejecutado por su Unidad Técnica de Medio Ambiente entre los años 1993 y1995 (UGT-CNCR 2010), situación que se contrapone a la información proveniente de documentos técnicos no publicados, muchos de ellos disponibles al público a través de la plataforma del SEA o como informes de investigación científica (FONDECYT), donde sí es posible obtener posiciones exactas mediante coordenadas y datum conocido (Tabla 1).

\section{Distribución de los datos}

La ubicación de los recursos patrimoniales arqueológicos en la Provincia de Cautín permite registrar ciertas concentraciones de puntos, en directa relación con su estrategia de obtención y el marco en el que la información fue generada. Se tiene por tanto una mayor agrupación de registros en la zona lacustre piemontana y cordillerana de la Provincia debido a la ejecución de proyectos de investigación (FONDECYT) y desarrollo (estos últimos en las comunas de Villarrica y Pucón), así como en las comunas centrales de la Región: Padre Las Casas y Temuco, relacionada a una mayor concentración de proyectos de desarrollo e inversión en estos sectores. Pese a existir recursos identificados en las zonas del valle central y costa, éstos se encuentran más dispersos y en menor cantidad, situación que se evidencia en las cantidades obtenidas de acuerdo a la división político-administrativa comunal (Figura 2 y Tabla $2^{16}$ ).

Por su parte, la exposición de la información de acuerdo a las subsubcuencas hidrográficas de la Provincia permite realizar observaciones a partir de 
Tabla1. Aspectos cuantitativos del posicionamiento de recursos arqueológicos en la Provincia de Cautín, según fuente. Quantitative aspects of the positioning of archaeological resources in Cautín Province, according to source.

\begin{tabular}{|c|c|c|c|c|}
\hline & $\begin{array}{l}\text { Superficie aprox. } \\
\text { de dispersión de } \\
\text { los datos }\left(\mathrm{km}^{2}\right)\end{array}$ & $\begin{array}{l}\text { Cantidad recursos } \\
\text { arqueológicos }\end{array}$ & $\begin{array}{c}\% \text { con ubicación } \\
\text { exacta, del total } \\
\text { general de RA }\end{array}$ & $\begin{array}{c}\% \text { con ubicación referencia } \\
\text { o sin información, del total } \\
\text { general de RA }\end{array}$ \\
\hline \multicolumn{5}{|l|}{ Cuerpo de datos 1} \\
\hline Informes Fondecyt & 7.702 & 173 & 49,13 & 0,87 \\
\hline \multicolumn{5}{|l|}{ Cuerpo de datos 2} \\
\hline Informes técnicos & 17.316 & 139 & 24 & 16,18 \\
\hline \multicolumn{5}{|l|}{ Cuerpo de datos 3} \\
\hline Bibliografía general & $10.085,7$ & 34 & 0 & 9,83 \\
\hline \multicolumn{5}{|l|}{ Totales } \\
\hline Provincia de Cautín & - & 346 & $73,13 \%$ & $26,88 \%$ \\
\hline
\end{tabular}

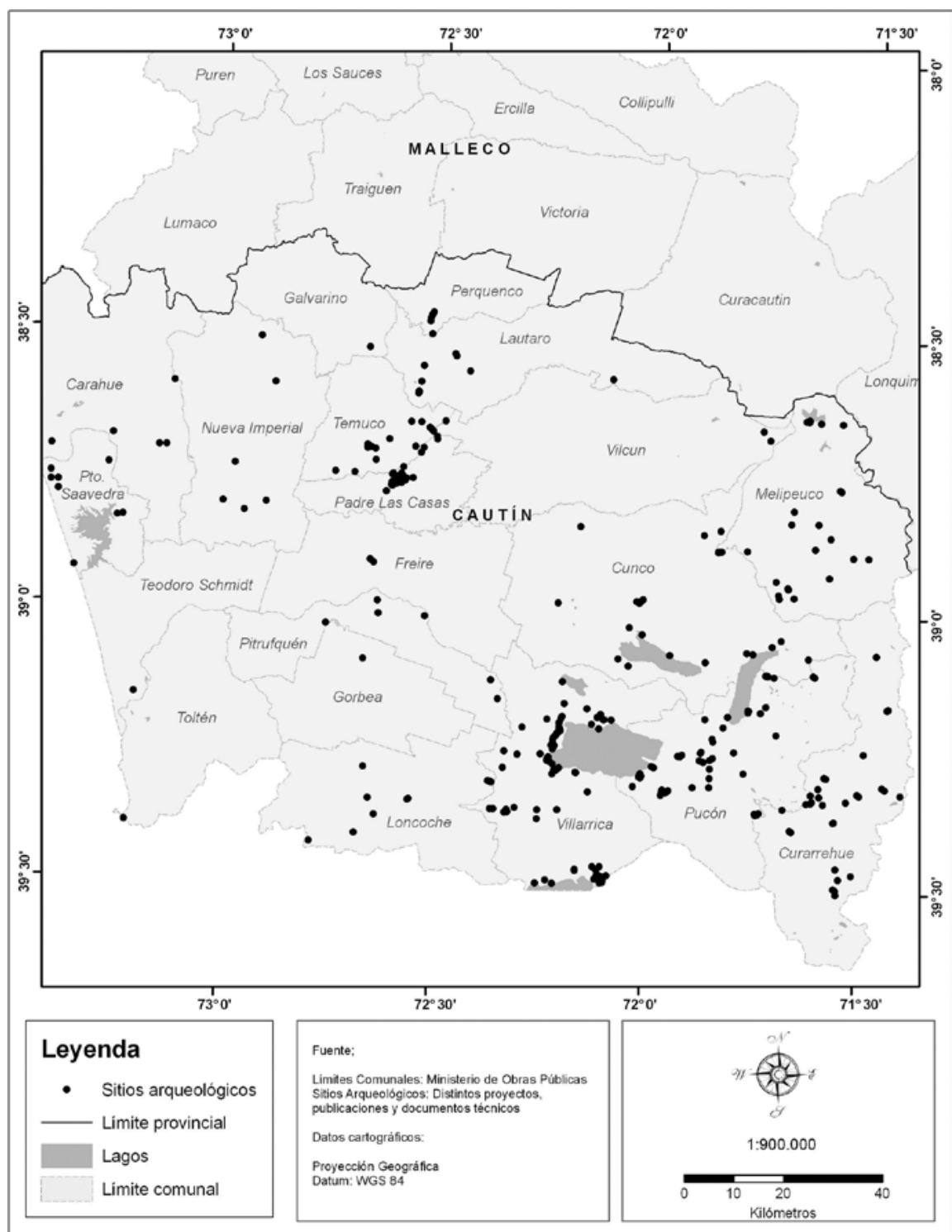

Figura 2. Posicionamiento de recursos arqueológicos en las diferentes comunas de la Provincia de Cautín. Positioning of archaeological resources in the different communes of Cautín Province. 
Tabla 2. Aspectos cuantitativos del posicionamiento de recursos arqueológicos en la Provincia de Cautín, según comunas. Quantitative aspects of the positioning of archaeological resources in Cautín Province, according to communes.

\begin{tabular}{lcccc}
\hline Comuna & $\begin{array}{c}\text { Superficie de la } \\
\text { comuna }\left(\mathrm{km}^{2}\right)\end{array}$ & $\begin{array}{c}\text { \% de la superficie } \\
\text { total de la Provincia }\end{array}$ & $\begin{array}{c}\text { Cantidad de RA } \\
\text { reconocidos }\end{array}$ & $\begin{array}{c}\text { \% de RA del total } \\
\text { de la Provincia }\end{array}$ \\
\hline Carahue & 1.341 & 7,25 & 5 & 1,45 \\
Chol Chol & 427,8 & 2,31 & 2 & 0,58 \\
Cunco & 1.907 & 10,32 & 21 & 6,07 \\
Curarrehue & 1.171 & 6,33 & 32 & 9,25 \\
Freire & 935 & 5,06 & 3 & 0,87 \\
Galvarino & 568 & 3,07 & 1 & 0,29 \\
Gorbea & 695 & 3,76 & 4 & 1,16 \\
Lautaro & 901 & 4,87 & 8 & 2,31 \\
Loncoche & 977 & 5,28 & 10 & 2,89 \\
Melipeuco & 1.107 & 5,99 & 23 & 6,65 \\
Nueva Imperial & 732 & 3,99 & 7 & 2,02 \\
Padre Las Casas & 400,7 & 2,17 & 34 & 9,83 \\
Perquenco & 331 & 1,79 & 6 & 1,73 \\
Pitrufquén & 580,7 & 3,14 & 5 & 1,45 \\
Pucón & 1.249 & 6,77 & 54 & 15,61 \\
Saavedra & 401 & 2,17 & 8 & 2,31 \\
Temuco & 464 & 2,51 & 30 & 8,67 \\
Teodoro Schmidt & 650 & 3,52 & 2 & 0,58 \\
Toltén & 936,8 & 5,06 & 1 & 0,29 \\
Vilcún & 1.421 & 7,69 & 4 & 1,16 \\
Villarrica & 1.291 & 6,98 & 346 & 24,28 \\
Sin referencia & - & - & & 0,58 \\
Totales & 18.487 & $100 \%$ & & $100 \%$ \\
\hline
\end{tabular}

unidades geomorfológicamente definidas, entregando una perspectiva sistémico-ambiental de los datos y contando con una unidad de análisis territorial, posible de utilizar en términos administrativos y de investigación (Figura 3 y Tabla 3).

\section{Un modelo general de trabajo para la incorporación de la arqueología en la planificación territorial local}

En términos prácticos, el instrumento de planificación territorial legalmente vigente que contempla de forma explícita a los Monumentos Nacionales y por ende al patrimonio arqueológico en el componente urbano, corresponde al Plan Regulador Comunal. De acuerdo al material revisado, durante la etapa de PT a nivel regional, el patrimonio arqueológico solo es considerado como parte de los antecedentes socioculturales de las memorias explicativas, desconociendo su naturaleza como recurso potencial inmerso en el territorio. Esto se debe principalmente a la situación legal de los PRC de la Región de La Araucanía (Gutiérrez y Peña-Cortés 2011) y a que durante el Análisis del Sistema Territorial (Gómez
2008) el componente arqueológico no es considerado en el subsistema del medio físico, sino que se lo limita al subsistema social, al cual pertenece, aunque no de forma exclusiva.

Dado que los recursos arqueológicos corresponden a contextos y materiales tangibles, cuya presencia es independiente a la esfera social "viva" y como depósitos se encuentran en el suelo y subsuelo (incluso subacuático), son recursos propios del llamado medio inerte ${ }^{17}$ (dimensión que en conjunto con el medio biótico y el medio perceptual conforman el medio físico) y que deben ser inventariados en el territorio y considerados en las etapas de generación $\left(1^{\circ}\right.$ Diagnóstico Integrado, $2^{\circ}$ Anteproyecto -memorias explicativas, planos y zonificaciones- y $3^{\circ}$ Evaluación Ambiental [en el SEA]) y ejecución de un plan, a través de la incorporación de especialistas en la elaboración de los estudios y documentos técnicos de gobernabilidad, planificación y gestión (Fernández 2008). Así como en los PRC, esta consideración se ajusta a los POT y PROT.

De acuerdo a los antecedentes revisados, se advierte que la generación de inventarios arqueológicos 


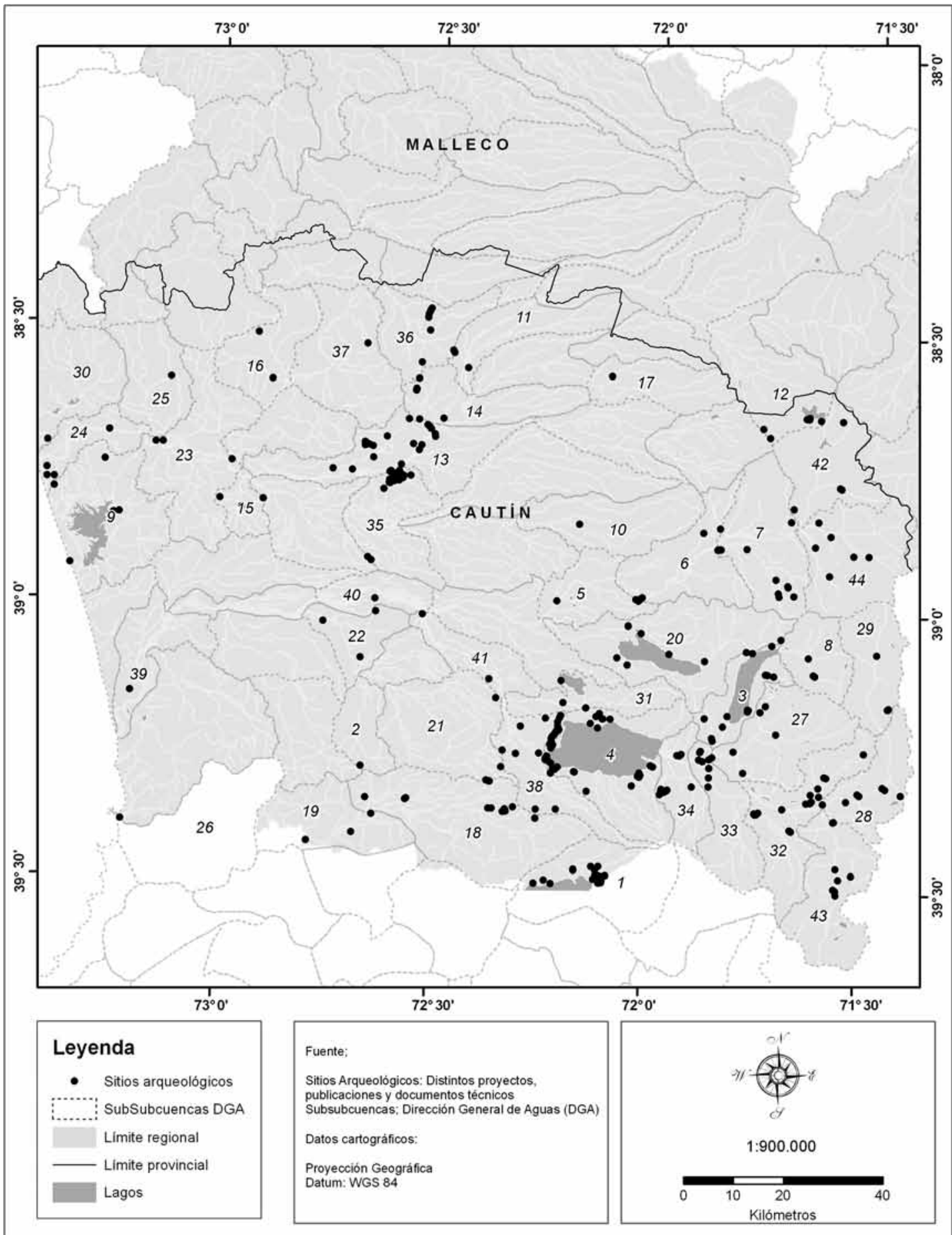

Figura 3. Posicionamiento de recursos arqueológicos en las diferentes subsubcuencas hidrográficas de la Provincia de Cautín. Positioning of archaeological resources in the different basins of Cautín Province. 
Tabla 3. Aspectos cuantitativos del posicionamiento de recursos arqueológicos [RA] en la

Provincia de Cautín, según subsubcuencas hidrográficas.

Quantitative aspects of the positioning of archaeological resources in Cautín Province, according to hydrographic basins.

\begin{tabular}{|c|c|c|c|c|c|}
\hline & Subsubcuenca & $\begin{array}{c}\text { Superficie } \\
\text { de la cuenca } \\
\left(\mathrm{km}^{2}\right)\end{array}$ & $\begin{array}{c}\% \text { de la } \\
\text { superficie total } \\
\text { de la Provincia }\end{array}$ & $\begin{array}{l}\text { Cantidad } \\
\text { de RA }\end{array}$ & $\begin{array}{c}\% \text { de RA del } \\
\text { total de la } \\
\text { Provincia }\end{array}$ \\
\hline 1 & Desagüe lago Calafquén desde desembocadura lago Coñaripe & 441,4 & 2,39 & 19 & 5,49 \\
\hline 2 & Estero Quitratue (Puyehue) & 155 & 0,84 & 1 & 0,29 \\
\hline 3 & Lago Caburgua y río Carrileufu en junta río Pucón & 194,8 & 1,05 & 15 & 4,34 \\
\hline 4 & Lago Villarrica & 497,3 & 2,69 & 33 & 9,54 \\
\hline 5 & Río Allipén entre estero Cunco y río Curaco & 215,4 & 1,17 & 4 & 1,16 \\
\hline 6 & Río Allipén entre río Llaima y bajo estero Cunco & 334,9 & 1,81 & 7 & 2,02 \\
\hline 7 & Río Allipén entre Tres Juntas y bajo río Llaima & 392,6 & 2,12 & 10 & 2,89 \\
\hline 8 & Río Blanco en desagüe lago Caburgua & 183,4 & 0,99 & 3 & 0,87 \\
\hline 9 & Río Budi & 497,3 & 2,69 & 5 & 1,45 \\
\hline 10 & Río Caihuico hasta bajo río Huichahue & 343,1 & 1,86 & 1 & 0,29 \\
\hline 11 & Río Cautín entre arriba junta estero Guacolda y río Muco & 267,1 & 1,44 & 3 & 0,87 \\
\hline 12 & Río Cautín entre estero Lefuco y bajo junta estero Collico & 379,6 & 2,05 & 7 & 2,02 \\
\hline 13 & Río Cautín entre estero Pumalal y río Quepe & 435,9 & 2,36 & 23 & 6,65 \\
\hline 14 & Río Cautín entre río Muco y bajo junta Estero Pumalal & 272,3 & 1,47 & 6 & 1,73 \\
\hline 15 & Río Cautín entre río Quepe y río Chol Chol & 91,7 & 0,5 & 3 & 0,87 \\
\hline 16 & Río Chol Chol entre río Quillén y río Renaco & 281,1 & 1,52 & 2 & 0,58 \\
\hline 17 & Río Collins & 237,2 & 1,28 & 1 & 0,29 \\
\hline 18 & Río Cruces (San José) bajo estero Niguen & 644,5 & 3,49 & 13 & 3,76 \\
\hline 19 & Río Cruces (San José) entre estero Niguen y río Leufucade & 326,2 & 1,76 & 3 & 0,87 \\
\hline 20 & Río Curaco & 561,4 & 3,04 & 7 & 2,02 \\
\hline 21 & Río Donguil bajo junta estero Polul & 439,4 & 2,38 & 2 & 0,58 \\
\hline 22 & Río Donguil entre estero Quitratue y río Toltén & 171,7 & 0,93 & 3 & 0,87 \\
\hline 23 & Río Imperial entre junta ríos Cautín y Chol Chol y río Las Damas & 497,5 & 2,69 & 3 & 0,87 \\
\hline 24 & Río Imperial entre río Las Damas y desembocadura & 162,4 & 0,88 & 4 & 1,16 \\
\hline 25 & Río Las Damas & 266,1 & 1,44 & 1 & 0,29 \\
\hline 26 & Río Lingue & 517,1 & 2,8 & 1 & 0,29 \\
\hline 27 & Río Liucura & 363,8 & 1,97 & 6 & 1,73 \\
\hline 28 & Río Maichín entre estero Cuatro M. y río Trancura & 237,4 & 1,28 & 6 & 1,73 \\
\hline 29 & Río Maichín hasta bajo estero Cuatro M. & 251,9 & 1,36 & 4 & 1,16 \\
\hline 30 & Río Moncul & 426,2 & 2,31 & 1 & 0,29 \\
\hline 31 & Río Pedregoso & 191,2 & 1,03 & 2 & 0,58 \\
\hline 32 & Río Pucón entre junta ríos Maichín y Trancura y bajo río Cavisani & 374,1 & 2,02 & 18 & 5,2 \\
\hline 33 & Río Pucón entre río Cavisani y río Curileufu & 240,9 & 1,3 & 9 & 2,6 \\
\hline 34 & Río Pucón entre río Curileufu y desembocadura lago Villarrica & 174,9 & 0,95 & 11 & 3,18 \\
\hline 35 & Río Quepe entre río Huichahue y Bajo estero Pelales & 294,3 & 1,59 & 32 & 9,25 \\
\hline 36 & Río Quillén entre puente Perquenco y estero Perquenco & 263,6 & 1,43 & 7 & 2,02 \\
\hline 37 & Río Ronaco & 422,8 & 2,29 & 1 & 0,29 \\
\hline 38 & Río Toltén entre desagüe lago Villarrica y río Pedregoso & 269,6 & 1,46 & 28 & 8,09 \\
\hline 39 & Río Toltén entre estero Neicuf y desembocadura & 255,6 & 1,38 & 1 & 0,29 \\
\hline 40 & Río Toltén entre río Allipén y río Donguil & 150,7 & 0,82 & 1 & 0,29 \\
\hline 41 & Río Toltén entre río Pedregoso y río Allipén & 176,9 & 0,96 & 2 & 0,58 \\
\hline 42 & Río Trafultraful & 324,7 & 1,77 & 4 & 1,16 \\
\hline 43 & Río Trancura & 360,8 & 1,95 & 8 & 2,31 \\
\hline \multirow[t]{3}{*}{44} & Río Zahuelhue y río Guallerrupe & 416,6 & 2,25 & 6 & 1,73 \\
\hline & Sin referencia & - & - & 19 & 5,49 \\
\hline & Totales & $14.002,4$ & $75,76 \%$ & 346 & $100 \%$ \\
\hline
\end{tabular}


a partir de las fuentes disponibles, como una primera fase de la consideración del componente en el OT, actualmente es una herramienta insuficiente para la generación de capas de información que permitan un adecuado manejo de los recursos (Fernández 2008), en concordancia con los demás intereses sectoriales (p.ej. proyecto MOP 1993-95). De acuerdo a esto, un IPT debería considerar la generación de información arqueológica, según los estándares actuales de registro, de una manera sistemática y estadísticamente válida, de acuerdo a las características ambientales y la superficie del territorio.

Al ser considerados en el Diagnóstico Integrado [DI] (Gómez 2008), los recursos arqueológicos cobran relevancia en las demás etapas del Análisis Territorial, y por ende en el OT, comenzando en los diagnósticos de problemas y potencialidades y posteriormente en la fase de preparación de la planificación -p. ej. en análisis FODA [fortalezas, oportunidades, debilidades y amenazas]-, la realización de pronósticos, la definición del sistema de objetivos, sus relaciones y la elaboración de un sistema que los compatibilice. Finalmente, el patrimonio arqueológico -considerando el conjunto de recursos prehispánicos, posthispánicos y aquellos entendidos como materia de estudio de las arqueologías Histórica e Industrial- debería encontrarse contenido en las propuestas, el modelo territorial a alcanzar y la generación de alternativas.

La información arqueológica debe ser vertida en los planos y zonificaciones, generando en una primera instancia las denominadas Cartas Arqueológicas ${ }^{18}$, cuya metodología de confección y utilización tiene una amplia gama de ejemplos a nivel internacional y algunos incipientes a nivel nacional (p.ej. Instituto Portugués do Patrimonio Arquitectónico e Arqueológico 1992; Poujade 1995; Berón y Curtoni 2002; CMN 2011). Las metodologías de levantamiento y procesamientos de los datos, según lo anteriormente evidenciado, debieran seguir una metodología científica de muestreo, que otorgara la posibilidad de acumular el conocimiento de una forma ordenada y útil para las venideras etapas de valoración y gestión o bien en la generación y aplicación de planes de manejo temáticos. En el marco de esta metodología científica, la segregación y análisis de la información de acuerdo a las cuencas hidrográficas de una región se convierte en el manejo de los datos más cercano a las características y elementos reales compartidos por un territorio (Dourojeanni 2000).
En términos teórico-prácticos, un modelo de planificación física con base ecológica (PeñaCortés y Mardones 1999) se torna adecuado para la consideración del patrimonio arqueológico en la PT. La Planificación Ecológica expone un marco teórico y una metodología para alcanzar las aptitudes de uso de suelo de acuerdo a las características físicas, contribuyendo a generar las bases del manejo sustentable de un territorio, por lo que es posible introducir el componente arqueológico como una de las variables del territorio a considerar en las matrices de evaluación y de oferta del espacio. En este marco, se considera cuáles han sido las principales razones que han originado un uso irracional de los recursos naturales, degradando el ambiente, las que tienen directa relación con los factores que son perjudiciales para los recursos culturales del medio físico, criterios que pueden ser extrapolados a la realidad del patrimonio arqueológico en forma independiente de los elementos socioeconómicos.

De acuerdo al diagnóstico realizado acerca del estado del patrimonio arqueológico a nivel institucional regional, es posible observar que una de las causas de la falta de consideración del componente corresponde a la escasez de información y al desconocimiento que se tiene de las fuentes. Se distingue que son muy pocas las situaciones que han considerado a un arqueólogo en la generación de los documentos técnicos, haciendo uso exclusivo de los antecedentes proporcionados por otras instituciones del Estado, en este caso, del Consejo de Monumentos Nacionales. Por su parte, actualmente el CMN no dispone de una plataforma de consulta donde las instituciones y especialmente las Municipalidades puedan acceder a la información sistematizada existente, acerca del emplazamiento y cantidad de recursos patrimoniales arqueológicos reconocidos en su territorio.

Los costos de generación de información debieran, por tanto, ser asumidos en el levantamiento de información local (en el marco de la generación de los IPT), a través de los presupuestos considerados en la confección de los planes, así como a través de programas y proyectos sectoriales (p.ej. Programa de Puesta en Valor del Patrimonio) y/o que surjan de la administración regional (GORE, SUBDERE, p.ej. a través del Fondo Nacional de Desarrollo Regional [FNDR]), con relación a las planificaciones regionales (PRDU o PROT) y locales (PRC y PRI). 
Los beneficios de la consideración del componente arqueológico en la planificación territorial tienen relación con el cumplimiento de la normativa y el adecuado conocimiento de las potencialidades y deberes en el manejo de un territorio, contemplando todas sus dimensiones, situación que actualmente es incluso evadida. El conocimiento patrimonial de un territorio es sustancial al momento de determinar su oferta, considerando intereses tanto públicos (políticos y sociales) como privados. Compatibilizar ambos intereses, de acuerdo a los lineamientos medioambientales de un territorio, se relaciona con la sinergia esperada para su desarrollo y permite tener una visión integral de sus potencialidades. En el caso de los recursos arqueológicos, diversos son los retornos que pueden esperarse de su consideración en la planificación, como efectos económicos positivos directos e indirectos (Fernández 2008), siendo relevante su conservación a través, por ejemplo, de la planificación de áreas verdes o esparcimiento relacionadas a recursos patrimoniales, en diferentes tipos o líneas de proyectos de carácter urbano o bien para la gestión de investigaciones específicas en Sitios de Especial Relevancia (Artículo $2^{\circ}$ Reglamento sobre Excavaciones y/o Prospecciones Arqueológicas, Antropológicas y Paleontológicas, Ley $\mathrm{N}^{\circ} 17.288$ ), acorde con otros objetivos territoriales. Asimismo, también se vuelve posible la anticipación a procesos de destrucción patrimonial, teniendo en cuenta la necesidad de realizar rescates de sitios arqueológicos en fases previas a la ejecución de proyectos de desarrollo e inversión, en aquellos sectores que presentarán intervenciones de subsuelo, permitiendo eventualmente a las comunas desarrollar planes y proyectos de trabajo en torno a estos recursos locales. Si bien sería esperable que a nivel municipal este trabajo fuera realizado de forma conjunta por la Secretaría Comunal de Planificación [SECPLAN] y las unidades de obras municipales y cultura, cabe recordar que según la Ley Orgánica Constitucional de Municipalidades solo aquellas comunas con más de 100.000 habitantes deben considerar más de una unidad de funciones genéricas (p.ej. desarrollo comunitario, obras municipales, aseo y ornato, tránsito y transporte públicos, administración y finanzas, asesoría jurídica y control) (Artículos $\mathrm{N}^{\circ} 15$ a 17 de la Ley $\mathrm{N}^{\circ} 18.695$ ), por lo que se debe reiterar que la arqueología de un territorio debe ser tratada como un componente más del medio físico, cuya responsabilidad pueda ser asumida en cualquier tipo de municipio a través de la SECPLAN y las instituciones relacionadas al GORE.

Con la aplicación de este modelo general de trabajo (Figura 4) y desde un punto de vista disciplinario, la arqueología aplicada aumenta su campo

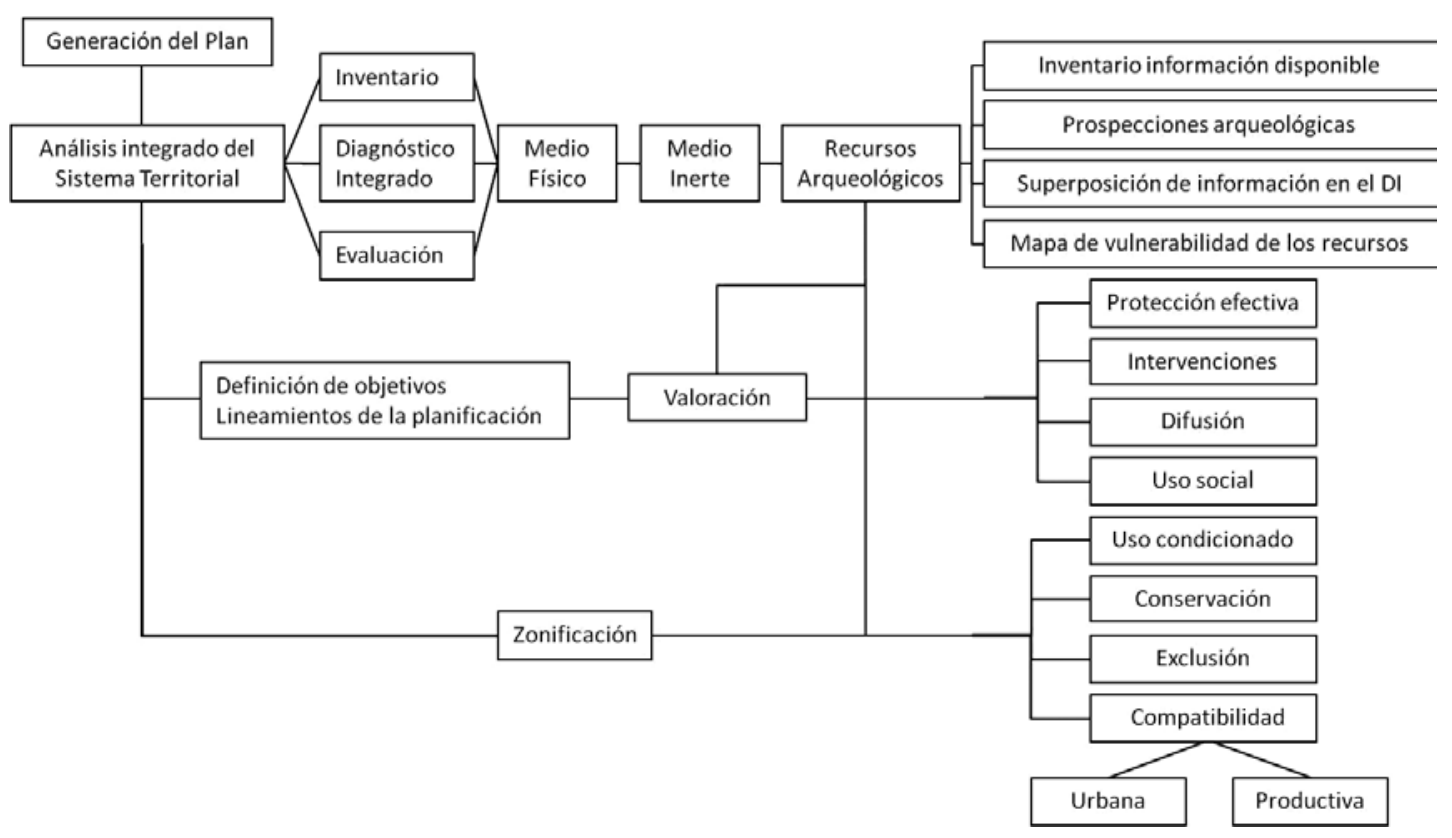

Figura 4. Esquema general de incorporación del componente arqueológico en los IPT a nivel regional y local. General scheme of incorporation of archaeological components in the IPT to at the regional and local levels. 
de acción, ya no solo a los estudios de impacto, sino que también a las zonificaciones (OGUC), generación de inventarios o cartas arqueológicas y cartas de riesgo (Fernández 2008), estableciéndose una suerte de equilibrio entre la producción de información por parte del ámbito público/privado y el exclusivamente público y considerando el componente arqueológico en la administración del territorio, al menos en el ámbito urbano. Estas propuestas corresponden a soluciones técnicas que permiten enfrentar el problema de la desconsideración del patrimonio arqueológico en la PT, aunque el trasfondo de su escasa integración en el ordenamiento del territorio es un tema mayor, que aún resta por ser ampliamente discutido, no solo desde la arqueología y la planificación territorial, sino también desde las perspectivas antropológica y de los pueblos ancestrales, atendiendo a la construcción de territorialidades e identidades locales.

\section{Conclusiones y Expectativas}

Todo objetivo o escenario de prospectiva que contenga elementos representativos del desarrollo cultural de una región, su identidad, arraigo de las culturas ancestrales, orígenes, historia, educación patrimonial e intereses especiales, es sustentable en la medida que sean propuestas y ejecuten políticas, planes, programas, proyectos e instrumentos de planificación, que aseguren la preservación y/o el adecuado trabajo sobre sus fuentes de información y materialización; en este caso, nos referimos a sus recursos patrimoniales arqueológicos. Si en los modelos sociales y territoriales a seguir, como parte de su imagen objetivo, se pretende una continuidad de estos elementos, es necesario considerar la condición tangible y expresión territorial de los recursos patrimoniales, en un contexto donde la tendencia apunta a su destrucción sistemática.

El patrimonio arqueológico, como un componente más del medio físico, supera la contingencia cultural de las regiones y si bien el modelo de trabajo propuesto se ajusta a toda la realidad nacional en términos administrativos, su objeto adquiere una valorización diferencial al encontrarse en territorios con una fuerte presencia de pueblos originarios. En este marco, cabe enfatizar que el tratamiento del patrimonio arqueológico en la planificación territorial (p.ej.: su consideración en los IPT) debe seguir lineamientos comunes en todo Chile, aunque también deberá responder a las realidades específicas de territorios donde se reconozca la presencia de comunidades ancestrales, enfocándose principalmente a la prevención de la destrucción de los recursos arqueológicos. Un ejemplo concreto de ello es la relación y recuerdo del uso de antiguos cementerios por parte de comunidades vivas. En este caso, durante la etapa de valoración en el Diagnóstico Integrado, el plan -además de considerar la presencia del recurso- deberá incorporar la variable de su conocimiento por parte de la comunidad y, por lo tanto, la no intervención sobre el sitio arqueológico y de relevancia antropológica. De esto se desprende la importancia que adquiere la etapa de valoración sobre el patrimonio arqueológico durante la elaboración de un plan y las diferencias que deben ser manejadas al momento de construir la PT de los territorios, dando cumplimiento a la normativa relacionada al patrimonio arqueológico y las culturas ancestrales desde una perspectiva territorial.

Gracias a la legislación vigente en Chile, relativa al patrimonio arqueológico y al medio ambiente, es posible reconocer una relación consecuente entre las intenciones constitucionales y la consideración de los recursos arqueológicos como bienes de la nación, a pesar de que aún no se ha realizado el vínculo entre políticas territoriales y políticas culturales, que den paso al cumplimiento cabal de objetivos relacionados a la valorización y puesta en valor del patrimonio arqueológico, así como a su adecuado tratamiento y conservación. Si bien la legislación chilena protege los recursos arqueológicos y existe un procedimiento claro acerca de las intervenciones sobre ellos, no existen normas detalladas acerca de su manejo a nivel territorial.

El desarrollo de estudios de levantamiento, sistematización e integración de la información arqueológica a nivel regional, relacionados con los demás aspectos de la planificación de un territorio, permitiría invertir en el reconocimiento patrimonial a corto plazo, utilizando la información recabada a largo plazo. Esto constituye la base de un ahorro futuro en cuanto a pérdidas patrimoniales, como acervo intelectual de una región, haciéndose necesaria la consideración del concepto de patrimonio tangible en las estrategias de desarrollo regional, tanto en las áreas urbanas como rurales, sobre todo en aquellas regiones que presentan una realidad multicultural.

Al momento de establecer una adecuada oferta del territorio, el trabajo de relevamiento y producción de conocimiento en etapas de PT es completamente atingente en marcos como el de la 
Evaluación Ambiental Estratégica, considerando la envergadura de los impactos en forma amplia o integral, en etapas previas a la toma de decisiones y asumiendo los efectos acumulativos de la ejecución y funcionamiento de obras de desarrollo (Iturriaga et al. 2006; Ley No 20.417; Comisión Nacional del Medio Ambiente-Centro de Estudios del Desarrollo [CONAMA-CED] 2010; Ministerio del Medio Ambiente [MIMA] y Ministerio de Vivienda y Urbanismo [MINVU] 2011).

Es función del Estado lograr que la información patrimonial se encuentre disponible distintamente, tanto para la gobernabilidad y desarrollo del país como para las necesidades de las personas. Actualmente en Chile una de las vías de generación de conocimiento arqueológico se encuentra en la consideración del componente en la ley de Bases del Medio Ambiente, lo que redunda en que un aporte sustantivo a nivel nacional es realizado por los privados, para quienes el conocimiento previo del patrimonio arqueológico de un territorio puede cooperar en la toma de decisiones acerca de cómo y cuándo invertir, teniendo en cuenta labores y costos que deben ser asumidos. A su vez, para que esta información pueda ser útil, debe ser sistematizada y actualizada; de acuerdo a la norma, estas labores son parte de los deberes del CMN ("Formar el Registro de Monumentos Nacionales y Museos"), situación que ha comenzado a ser trabajada formalmente, a través de la generación de los "Estándares mínimos de registro del Patrimonio Arqueológico" y el "Geoportal-CMN" (UGP-CNCR 2010; Núñez et al. 2012). Si bien estas iniciativas, de acuerdo a los objetivos referidos a la implementación de plataformas de información para la gestión institucional, constituyen la base de la consideración del patrimonio arqueológico en el territorio, se vislumbra que los tiempos de implementación de las etapas venideras por parte de las instituciones presentan un desfase con relación a la generación y puesta en práctica de los IPT y se encontrarían centradas en la sistematización y disponibilidad de los datos y no en la generación de datos de campo para las etapas de planificación. Es por esto que se propone asumir una responsabilidad compartida entre las diferentes instancias de gobierno (desde el nivel central hasta los municipios), para la preservación de nuestro patrimonio arqueológico en términos territoriales.

En la búsqueda de la compatibilidad territorial entre intereses sectoriales, la incorporación del componente arqueológico en la planificación del territorio es coherente y factible de concretar en los distintos niveles del OT regional, teniendo en cuenta, además, el reciente comienzo de un proceso de modificación de la institucionalidad cultural en Chile, que involucrará un cambio en la dependencia del CMN y la DIBAM y modificaciones en la Ley de Monumentos Nacionales, existiendo la posibilidad de articular consejos regionales, en directo vínculo con el traspaso de competencias desde el Gobierno Central a los GORES.

Agradecimientos: Especialmente a Rodrigo Mera y Jimmy Pincheira por su constante apoyo durante la elaboración de este trabajo. Agradecemos también a Leonor Adán, Carlos Ocampo, Ximena Navarro, Andrea Ponce y a todos quienes nos compartieron importante información. Al Laboratorio de Planificación Territorial y al Programa de Magíster en Planificación y Gestión Territorial, Escuela de Ciencias Ambientales, Facultad de Recursos Naturales, Universidad Católica de Temuco. También queremos agradecer a los evaluadores de este artículo, por sus valiosas correcciones y acuciosos comentarios.

\section{Referencias Citadas}

Aceituno, F. 1998. Arqueología y desarrollo sostenible en Colombia. Complutum 9:335-344.

Adán, L. (compil.) 2010. Informe de diagnóstico y valorización del patrimonio arqueológico de la Región de Los Ríos. Manuscrito en posesión de la autora.

Adán, J., L. Adán y P. Peña 2009. Metodología de valoración para bienes patrimoniales de la Región de Los Ríos. Diagnóstico del Patrimonio Cultural de la Región de Los Ríos. Gobierno Regional de Los Ríos, Universidad Austral de Chile. Manuscrito en posesión de los autores.
Araneda, E. 2002. Uso de Sistemas de Información Geográficos y análisis espacial en arqueología: Proyecciones y limitaciones. Estudios Atacameños 22:59-75.

Berón, M. y R. Curtoni 2002. Atlas Arqueológico de la Provincia de La Pampa. Serie monográfica, volumen 2. Universidad Nacional del Centro de la Provincia de Buenos Aires.

Carver, M. 1996. On Archaeological value. Antiquity 70:45-56.

CMN 2011. Ley $N^{o} 17.288$ de Monumentos Nacionales y normas relacionadas. $5^{a}$ edición actualizada. Ministerio de Educación, Consejo de Monumentos Nacionales, Santiago. 
_ _ _ 2011. Catastro arqueológico de la Provincia de Llanquihue. Ministerio de Educación, Consejo de Monumentos Nacionales, Santiago, manuscrito en posesión de los autores.

CNCA Región de La Araucanía 2005. La Araucanía quiere más Cultura. Entre la Paz y la Esperanza. Definiciones de Política Cultural Región de La Araucanía 2005-2010.

CINU 2010. La UNESCO y la protección de patrimonio cultural. (22 agosto 2002). http://www.cinu.org.mx/eventos/cultura2002/ unesco.htm (9 enero 2013).

CONAMA-CED 2010. Consultoría "Marco conceptual para la implementación de la Evaluación Ambiental Estratégica (EAE) en Chile". Informe final.

Dourojeanni, A. 2000. Procedimientos de gestión para el desarrollo sustentable. Serie Manuales, División de Recursos Naturales e Infraestructura, CEPAL-ECLAC, Naciones Unidas.

Fernández, S. 2008. Patrimonio Arqueológico y Planificación Territorial. Estrategias de Gestión para Andalucía. Secretariado de publicaciones, Universidad de Sevilla, Sevilla.

Gómez Orea, D. 2008. Ordenación Territorial. Mundi-Prensa y Editorial Agrícola Española S.A. Madrid.

Gobierno Departamental de San José 2011. Plan Local de Ordenamiento Territorial de Kiyú y sus vecindades, Departamento de San José. Convenio Gobierno Departamental de San José, Ministerio de Vivienda, Ordenamiento Territorial y Medio Ambiente (MVOTMA) - Dirección Nacional de Ordenamiento Territorial (DINOT), Uruguay.

González, P. 2001. Régimen jurídico de protección del patrimonio cultural y de los pueblos indígenas en la legislación chilena. Memoria para optar al grado de Licenciado en Ciencias Jurídicas y Sociales, Departamento de Derecho Privado, Facultad de Derechos, Universidad de Chile, Santiago.

GORE 2010. Estrategia Regional de Desarrollo Araucanía 2010-2022. Gobierno Regional de La Araucanía (20 enero 2012). http://www.subdere.gov.cl/documentacion/araucania-estrategiaregional-de-desarrollo-periodo-2010-2022 (9 enero 2013).

Grupo de Educación Gestión en Cultura y Educación Ambiental 2009. Aportes a la formulación e implementación del plan de manejo arqueológico en áreas del paisaje cultural cafetero, Departamento de Risaralda. Facultad de Ciencias Ambientales, Universidad Tecnológica de Pereira. Colombia.

Gutiérrez, G. y F. Peña-Cortés 2011. Estado y situación actual de los planes reguladores comunales en la región de La Araucanía (Chile). Documentos y aportes en administración pública y gestión estatal (DAAPGE) 16:97-119.

Herrero, L. 2002. La economía de la cultura en España: una disciplina incipiente. Revista Asturiana de Economía 23:147-175.

Hodder, I. y C. Orton 1990. Análisis Espacial en Arqueología. Editorial Crítica, Barcelona.

ICOMOS 2007. Declaración de Teemaneng. Sobre el Patrimonio Inmaterial de los espacios culturales. Kimberley (Teemaneng), Northern Cape.

IDER-UFRO 2008. Del Frío Misterio a la Responsabilidad Cultural Araucanía. Resultados del Estudio para el Fortalecimiento de la Identidad Regional Araucanía. Estudio para el Fortalecimiento de la Identidad Regional, Dirección de Planificación y Desarrollo Regional Gobierno Regional de La Araucanía.

Instituto Portugués do Patrimonio Arquitectónico e Arqueológico 1992. Carta Arqueologica da Portugal. Secretaria de Estado da Cultura, Lisboa.

Iturriaga, J., F. Riquelme y J. Rovira 2006. Evaluación Ambiental Estratégica: la Experiencia de los Planes Regionales de Desarrollo Urbano y Territorial. Ediciones Universidad Mayor / Serie Documentos Técnicos, Santiago.

Ladrón de Guevara, B., P. García, R. Prieto y J. Riveros 2007. Desarrollo de la Unidad de Geoinformación del Patrimonio (UGP) en el CNCR: patrimonio, territorio y gestión pertinente. Conserva 11:119-136.

Llavori de Micheo, R. 1998. Arqueología y planificación territorial. Un procedimiento aplicado a la arqueología medioambiental. Complutum 9:311-334.

López, C., M. Cano, C. Henao y M. Ocampo 2010. Aportes de la arqueología a la planificación territorial: Interdisciplina, paisajes culturales y gestión patrimonial. Caso Departamento de Risaralda, Colombia. International Journal of South American Archaeology 7:23-38.

LPT-UCT 2007. Plan de ordenamiento territorial cuenca del Lago Ranco. Laboratorio de Planificación Territorial, Universidad Católica de Temuco.

Mariné, M. 1996. La Convención de Malta. Hacia una arqueología europea. Complutum Extra 6:273-282.

Massiris, A. 2002. Ordenación del Territorio en América Latina. Scripta Nova VI (125). Barcelona, España.

Mera, R. y D. Munita 2007. Proyecto POT Lago Ranco. Componente Arqueológico. Informe Final. Propuestas. Manuscrito en posesión de los autores.

- - - 2008. Dinámicas territoriales de construcción de identidad en la larga duración: el conocimiento arqueológico sobre La Araucanía. Estudio para el Fortalecimiento de la Identidad Regional, Región de La Araucanía, Primera etapa. Informe de avance: 29-68. Manuscrito en posesión de los autores.

MOP 2010. Diagnóstico Patrimonio Cultural Región de Los Ríos. Programa Puesta en Valor del Patrimonio. Gobierno Regional Región de Los Ríos, Gobierno de Chile.

MIMA y MINVU 2011. Guía para la Evaluación Ambiental Estratégica de los Planes de Desarrollo Urbano, Planes Reguladores Intercomunales, Planes Reguladores Comunales y Planes Seccionales. Gobierno de Chile.

Munita, D., L. Adán y C.R. Mera 2010. Prospecciones arqueológicas terrestres en áreas lacustre piemontana, cordillerana y pampeana del centro sur chileno. Magallania 38:247-268.

Munita, D. y A. Farías 2011. Base de datos de recursos arqueológicos de la Provincia de Cautín. Manuscrito en posesión de los autores.

Núñez, G., M. González y F. Silva 2012. Geoportal-CMN: visualización de los monumentos nacionales en el territorio. Ponencia presentada en XIX Congreso Nacional de Arqueología Chilena, Arica.

Peña-Cortés, F. y M. Mardones 1999. Planificación Ecológica en el curso inferior del río Itata. VIII región del Bío Bío. Revista Geográfica de Chile Terra Australis 44:45-62. 
Poujade, R.A. 1995. Mapa Arqueológico de la Provincia de Misiones. Secretaría de Estado de Cultura de la Provincia y Entidad Binacional Yacyretá. Misiones.

Querol, M.A. y B. Martínez 1996. El Patrimonio arqueológico en la normativa internacional. Complutum Extra 6:295-306.

Ramírez, J.M. 2004. Manejo del recurso arqueológico en Rapa Nui: Teoría y Realidad. Chungara Revista de Antropología Chilena 36, número especial, tomo I, pp. 489-497.

Rodríguez, G. 1996. Gestión del patrimonio arqueológico en Gran Bretaña. SPAL Revista de Prehistoria y Arqueología de la Universidad de Sevilla 5:9-18.

Ropert, R. y R. Saavedra 2004. La protección del Patrimonio Cultural en la Ley 19.300 de Bases Generales del Medio Ambiente a la luz de dos sentencias recientes. Revista de Derecho Consejo de Defensa del Estado 11.
Rozzi, R., F. Massardo, A. Mansilla, C.B. Anderson, A. Berghöfer, M. Mansilla, M.R. Gallardo, J. Plana, U. Berhöfer, X. Arango, S. Russell, P. Araya y E. Barros 2006. La reserva de Biósfera Cabo de Hornos: Un desafío para la conservación de la biodiversidad e implementación del desarrollo sustentable en el extremo austral de América. Anales del Instituto de la Patagonia 35:55-70.

SUBDERE 2011. Plan Regional de Ordenamiento Territorial. Contenido y Procedimientos. Departamento de Políticas y Descentralización. División de Políticas y Estudios, Santiago.

UGP-CNCR 2010. Estándares Mínimos de Registro del Patrimonio Arqueológico. Área de Patrimonio del Sistema Nacional de Coordinación de Información Territorial (SNIT). Centro Nacional de Conservación y Restauración DIBAM y Consejo de Monumentos Nacionales, Santiago.

\section{Notas}

1 "La planificación territorial es la segunda fase del proceso de elaboración de un plan de ordenamiento del territorio... Consiste, básicamente, en diseñar, en función del diagnóstico elaborado, un modelo territorial o imagen objetivo que se desea conseguir a largo plazo..." (Gómez 2008:451). En términos generales, la planificación engloba las fases de análisis y planificación territorial, distinguiéndose de la gestión, que se considera como la puesta en práctica y seguimiento de un plan.

2 “...la ordenación del territorio se materializa a través de la elaboración y ejecución de un conjunto de planes (instrumentos legales para la ordenación territorial), que pueden ser específicos de la ordenación del territorio o corresponder a otros campos...;" (Gómez 2008:135). En Chile, la planificación urbana se realiza mediante diversos instrumentos de planificación territorial de acuerdo a la escala de planificación (Plan Regional, Plan Regulador Intercomunal, Plan Regulador Comunal, Plan Seccional y Límite urbano).

3 El hallazgo fortuito de sitios con significación cultural como son los recursos arqueológicos, en la mayoría de las situaciones es considerado como un problema que debe ser resuelto esencialmente por los privados, según las normas del Estado, sin reportar beneficios para los inversionistas. Es así como en reiteradas ocasiones, en el marco de ejecución de obras, se ha omitido y omite el hallazgo de evidencias arqueológicas que representan atrasos en los plazos de entrega y gastos no considerados en la realización de proyectos de desarrollo.

4 El concepto de Oferta del Espacio, si bien puede ser considerado como un término de corte economicista en la concepción del territorio (malentendiendo que el concepto alude a "la venta del territorio"), se torna adecuado de utilizar al momento de proponer el para qué puede ser utilizado un espacio en planificación territorial. Este concepto ha sido incorporado en el marco de la Planificación Ecológica (Peña y Mardones 1999), de acuerdo a las aptitudes o usos óptimos de un territorio para el desarrollo de actividades definidas, productivas y de conservación, de acuerdo a sus propias características, privilegiando sus reales potencialidades y respetando los recursos existentes, por sobre modelos de utilización del espacio en que solo prima un interés económico de explotación.

5 Dada su geografía, en Chile existen importantes diferencias en la conservación de los restos arqueológicos a lo largo del territorio, que juegan un rol fundamental en la valoración otorgada por la población al patrimonio arqueológico. Mientras en el norte de Chile (específicamente en el ambiente desértico) es posible el hallazgo de casi todas las materialidades (incluso orgánicas) y las evidencias se encuentras muchas veces expuestas (p.ej.: arquitectura), en el sur del país -en términos generales- solo es posible hallar elementos inorgánicos y los rasgos arqueológicos en numerosas ocasiones se encuentran invadidos por vegetación. Esto influye en que el patrimonio arqueológico sea mayormente considerado en regiones donde es posible su observación directa o se reconozcan elementos más llamativos de la cultura material, en desmedro de aquellas regiones donde el registro arqueológico es más restringido y presenta mayores dificultades de hallazgo e interpretación, aunque sea tan frecuente y relevante como en ambientes que permiten una mejor conservación de las evidencias.

6 Tratado internacional en el que destaca “....algo que antes no se había tenido en cuenta respecto a la conservación y gestión del PA [patrimonio arqueológico], su indisoluble unión con la planificación de los territorios" (Querol y Martínez 1996). Asimismo, se refiere la importancia de la consideración del Patrimonio Arqueológico en las etapas de planificación urbana y rural y se establece la necesidad de generar catastros o inventarios del patrimonio arqueológico.

7 En este tratado internacional, el patrimonio arqueológico es considerado como una riqueza no renovable (Querol y Martínez 1996).

8 La Convención para la Protección del Patrimonio Mundial Cultural y Natural de la UNESCO (1972) es el único instrumento internacional ratificado por Chile acerca de la protección del patrimonio cultural general (González 2001).

9 Modificada por la Ley No 20.417 que crea el Ministerio, el Servicio de Evaluación Ambiental y la Superintendencia del Medio Ambiente. 
10 Una revisión de la normativa nacional e internacional ratificada, relacionada al patrimonio arqueológico, puede ser consultada en: www.monumentos.cl (CMN 2011).

11 Artículo 2.1.10 sobre el Expediente del PRC, OGUC.

12 Información oficial acerca de la institucionalidad chilena referida, se encuentra en las siguientes direcciones: http://www.subdere.gov.cl/gobiernos-regionales (para información de GORES); http://www.arquitecturamop. cl/Patrimonio/Paginas/default.aspx (para información del MOP, Dirección de Arquitectura DAMOP y Programa de Puesta en Valor del Patrimonio PPVP); http://www.cncr.cl/ Vistas_Publicas/publicContenido/contenidoPublicDetalle. asp $x$ ?folio $=3817 \&$ idioma $=0$ (para información del CNCR y UGP).

13 Actualmente, la información recabada -tanto bases de datos como SIG- se encuentra en posesión de los autores.

14 Cabe tener en cuenta que los recursos arqueológicos reconocidos en el marco de proyectos de investigación o planificación tienen la posibilidad de ser considerados en etapas de planificación territorial y/o estar sujetos a planes de manejo (intervenciones controladas, conservación, etc.), mientras que aquellos recursos identificados según los mecanismos del SEA, ya se encuentran intervenidos o susceptibles de serlo y en la mayoría de los casos no existen alternativas de tratamiento más que su intervención y destrucción.

15 En la investigación bibliográfica, se utilizaron fuentes previas y posteriores al año 2000.

16 Para la Provincia de Cautín se consideró una superficie total de $18.487 \mathrm{~km}^{2}$, cifra que corresponde a la sumatoria de las áreas comunales consultadas en fuentes oficiales (www. subdere.cl y páginas municipales) y extraoficiales (en el caso de no existir el dato en la respectiva página oficial). Debido a esto, es que existen diferencias de este dato con relación a otras fuentes.

17 Al considerar al patrimonio arqueológico como parte del medio físico y más específicamente como parte del denominado medio inerte, se está haciendo alusión únicamente a su dimensión material, excluyendo por supuesto las interpretaciones implícitas y significancia del patrimonio arqueológico, relativas a las procesos sociales del pasado, prácticas, cotidianeidad y cambios culturales, etc.

18 Similares a las Cartas Geológicas, constituidas por un mapa $\mathrm{y}$ un texto explicativo. 